Vol. 23, No. 3, pp. 234 243, 2020.

\title{
Research Trends of Transparent Ceramics for Military Applications
}

\author{
Wook Ki Jung, Kisu Lee, Jaeho Choi ${ }^{\dagger}$
}

Agency for Defense Development, Yuseong P.O. Box 35, Daejeon 34186, Republic of Korea

\section{군용 투명세라믹스 연구동향}

\author{
정욱기, 이기수, 최재호 ${ }^{\dagger}$ \\ 국방과학연구소
}

(Received September 2, 2020; Revised September 14, 2020; Accepted September 18, 2020)

\begin{abstract}
s
Transparent ceramics are widely considered in military applications such as transparent armor, electrooptical window and domes, and high power solid-state laser hosting components. Advanced fabrication technologies of polycrystalline ceramics have enabled us to make transparent ceramics with outstanding thermal, mechanical and optical properties which were not possible before. The existing properties of the ceramics, however, need to be improved for the applications of future military systems. Here, we reviewed the studies on the characteristics and the fabrication methods of these transparent ceramics.
\end{abstract}

Keywords: Transparent ceramics, Military application, Characteristics, Fabrication technologies

\section{1. 서론}

다결정 세라믹 소결 기술이 고도화됨에 따라, 우수한 광학적, 기계적, 열적 물성을 가지는 투명세라믹 소재 관련 연구가 활발히 진행되어 왔다. 특히, 투명세라믹
소재의 물성을 이론적 한계까지 높이기 위해서는 고순 도 분말 합성 기술과 함께 미세구조 제어와 같은 세라믹 공정 연구가 매우 중요하게 고려되어야 한다 ${ }^{1)}$. 이러한 다결정 투명세라믹 소재는 군수분야에서 전자광학 창 ${ }^{2)}$, 투명 방탄소재 ${ }^{2,3)}$ 및 고체 레이저용 호스트 ${ }^{4)}$ 등으로 응

${ }^{\dagger}$ Corresponding Author: Jaeho Choi

E-mail: wjddnrrl12@naver.com 
용되고 있다. 기계적 강도가 우수한 $\mathrm{AlON}$ (Aluminum Oxynitride)은 대표적인 방탄소재로 연구가 활발히 진행되었으며, $\mathrm{MgAl}_{2} \mathrm{O}_{4}, \mathrm{Y}_{2} \mathrm{O}_{3}-\mathrm{MgO}$ 나노복합소재, Sapphire $\left(\mathrm{Al}_{2} \mathrm{O}_{3}\right), \mathrm{ZnS}$ 등은 적외선 파장 대역에서 투 과 특성이 우수하여 전자광학 창 등의 용도로 많은 연구 가 진행되었다. 또한, 열전도도가 우수한 $\mathrm{Y}_{2} \mathrm{O}_{3}, \mathrm{Lu}_{2} \mathrm{O}_{3}$ $\mathrm{Sc}_{2} \mathrm{O}_{3}$ 와 같은 삼이산화물들은 고출력 고체 레이저 응용 을 위한 호스트 소재로 주목을 받았으며, 앞서 언급된 $\mathrm{MgAl}_{2} \mathrm{O}_{4}$ 는 레이저 창 소재로 각광받고 있다. 이와 같 이 각각의 투명세라믹 소재들은 그 자체로 우수한 물성 을 지니고 있지만, 더 가혹한 환경에서 사용되기에는 여 전히 한계가 있기 때문에 이를 극복하기 위한 다양한 연 구들이 진행되고 있다. 본 논문에서는 군수 분야에 응용 가능한 투명세라믹 소재들을 소개하고, 제조 공정에 따 른 특성 관련 연구동향을 살펴보고자 한다.

\section{2. 본론}

\section{1 방탄용 투명세라믹}

전통적인 투명방탄소재는 투명 폴리머 필름과 같은 유기소재 또는 유리를 다층으로 접착하여 제조하는 방 식으로 연구되어 왔다 ${ }^{5)}$. 1970년대에는 페닐(phenyl)기 의 선형적 결합 구조로 인해 강한 내충격성을 가지는 폴 리카보네이트(polycarbo- nate)계 투명방탄소재가 많 이 연구되었다.

독일 Schott사는 붕규산염 유리(borosilicate)를 이 용하여 투명방탄의 경량화에기여하였으며, 이탈리아 Isoclima사는 1980년대 초 glass 및 polycarbonate의 다층 복합구조를 최적화하여 방탄유리 개발에 응용하였 다. 이후에 무게가 가벼운 $\mathrm{AlON}, \mathrm{MgAl}_{2} \mathrm{O}_{4}$ 와 같은 새 로운 투명세라믹 소재들이 개발되면서 휴대성과 방탄능 력을 동시에 고려한 진일보한 투명방탄소재 개발의 역 사가 이어져 왔다.

기존의 유리계 투명방탄소재의 단점인 무게와 크기 의 한계를 극복하기 위해서는 새로운 소재가 필요했고, 1959년 제네럴일렉트릭(General Electric)사의 R. L. Coble에 의해 세계 최초로 투명 $\mathrm{Al}_{2} \mathrm{O}_{3}$ 세라믹이 개발되
면서 광학적, 기계적, 열적, 전기적 물성이 우수한 투명 세라믹 소재의 연구개발이 활발해질 수 있었다. 이에 유 리계 투명방탄소재의 대안으로 투명방탄세라믹이 대두 되었으며, 그중 단결정 $\mathrm{Al}_{2} \mathrm{O}_{3}$ 인 Sapphire와 $\mathrm{AlON}$, 그리 고 $\mathrm{MgAl}_{2} \mathrm{O}_{4}(\mathrm{Mg}$ spinel $)$ 소재가 대표적으로 알려졌다 ${ }^{6}$. 최근에는 미국을 비롯하여 프랑스, 독일, 일본, 이탈리 아 등 많은 국가들이 방탄용 투명세라믹 기술을 개발해 오고 있다.

국내에서는 연세대에 설치된 국방나노응용특화연구센 터(방위사업청, 국방과학연구소)의 개별과제를 통해 강 화된 붕규산염 유리를 적층하여 경량화, 박형화 방탄소 재 제조기술을 개발하였으며, 우수한 방탄성능을 확인 하였다. 또한, 민간에서도 핵심방산소재사업을 통해 $\mathrm{Mg}$ spinel과 $\mathrm{AlON}$ 투명세라믹을 제조하여 방탄성능을 확인 한 바 있다. 국내에서 개발된 투명방탄세라믹 소재는 기 존 방탄유리 대비 $200 \%$ 이상의 방탄 성능을 보여준다.

\subsubsection{Sapphire}

사파이어는 투명세라믹 중에서 가장 널리 사용되는 소재 중 하나로, 반도체 등 민수 분야뿐만 아니라 군수 분야에서도 투명방탄, 전자광학 창 등의 용도로 연구 및 적용되고있다. 일반적으로 Rhombohedral 결정구조를 갖는 $\mathrm{Al}_{2} \mathrm{O}_{3}$ 는 광학적 이방성을 갖기 때문에 다결정 형 태로는 입계산란이 심하여 가시광 영역에서 투광성을 확보하는 데 어려움이 있다. 따라서, $\mathrm{Al}_{2} \mathrm{O}_{3}$ 의 단결정화 (사파이어)를 통해 투광성을 확보할 수 있다. 사파이어 를 제조하기 위해서는 단결정 성장 기술이 필요하며, 프 랑스 Saint-Gobain사는 사파이어의 크기를 15 인치 이 상 키우는 기술을 개발하였다. 그러나, 사파이어의 크기 가 점점 증가함에 따라 단결정 성장과 표면연마 및 가공 에 많은 시간과 에너지가 소모되기 때문에 가격이 급증 하는 단점이 있다 ${ }^{7)}$. 이를 극복하기 위해서 미국 Army Research Laboratory(ARL), Center for Optics Manufacturing과 같은 연구기관에서는 표면가공에 소 요되는 비용을 최소화할 수 있는 연마기술들을 병행하 여 개발하고 있다. 
특 집 ㅁㅁ정욱기, 이기수, 최재호

\subsubsection{AION}

$\mathrm{AlON}$ 은 $\mathrm{Al}_{2} \mathrm{O}_{3}$ 와 비슷하게 주로 알루미늄과 산소로 이루어져 있으나, 질소가 소량 첨가됨으로써 cubic 안정 상인 $\gamma-\mathrm{AlON}\left(\mathrm{Al}_{(64+\mathrm{x}) / 3} \mathrm{O}_{32-\mathrm{x}} \mathrm{N}_{\mathrm{x}}\right)$ 을 형성할 수 있다. 따라 서, 광학적 이방성이 존재하지 않고, $\mathrm{Al}_{2} \mathrm{O}_{3}$ 와 유사하게 화학적 안정성을 가질 수 있다. $\mathrm{AlON}$ 투명세라믹은 자 외선(UV)부터 중적외선(MWIR)까지 매우 넓은 파장대 역에서 우수한 투과율 (T>80\% @0.25-4 $\mu \mathrm{m}$ )과 함께 높은 기계적 물성(강도 300-700 MPa), 고온 저항성 및 열충격성을 가진 소재로 알려져 있다. 또한, 기존 사파 이어 제조공정과 비교했을 시, 다결정으로 제조할 수 있 기 때문에 크기 성장에 제약이 덜한 장점이 있다8).

상기에 언급된 바와 같이, $\mathrm{AlON}$ 투명세라믹은 다결 정으로 제작할 수 있다는 장점으로 인하여 세라믹 분 말 프로세싱(Powder synthesis)에서 출발하여 건식성 형(Green body shaping)-소결(Sintering)-HIP(Hot Isostatic Pressing)공정을 통해 제작이 가능하며, 최종 표면가공(Optical fabrication)을 통해 완성된다(Fig. 1) ${ }^{9}$. 분말은 $\mathrm{AlON}$ 상을 가진 초기 분말로 소결할 수도 있지 만, $\mathrm{Al}_{2} \mathrm{O}_{3}$ 와 $\mathrm{AlN}$ 혼합분말을 이용, 반응소결을 유도하여 치밀화를 이룰 수 있으며 $\mathrm{AlON}$ 상은 $1400{ }^{\circ} \mathrm{C}$ 이상에서 형성되는 것으로 잘 알려져 있다 ${ }^{10)}$.
1946년 Yamaguchi 가 최초로 $\gamma-\mathrm{AlON}$ 스피넬구조 가 $1,000{ }^{\circ} \mathrm{C}$ 까지 안정하다는 사실을 밝힌 후 1960 년도 에 많은 프랑스 연구자들이 $\mathrm{AlON}$ 소재의 상태도와 제 조기술을 연구하였고, 미국을 중심으로 많은 국가에서 군수용 투명세라믹소재로 $\mathrm{AlON}$ 을 개발해 왔다. 일례로 미국의 방산업체인 Raytheon사에서는 2002년에 AlON 제조기술 및 연구개발 성과를 Surmet사로 기술이전하 면서, Surmet사가 현재까지도 가장 우수한 AlON 투명 세라믹을 제조기술 보유업체 중 하나로 자리매김하고 있다. 특히 Surmet사는 $\mathrm{AlON}$ 분말 합성기술부터 다양 한 형태의 소결 완제품 생산에 이르기 까지 매우 성숙 된 기술을 보유하고 있으며, $70 \mathrm{~kg} \mathrm{AlON}$ 투명방탄소재 를 $46 \times 24 \times 12.5$ 인치 크기까지 만들 수 있는 것으 로 파악된다. 또한, 방탄시험결과 $\mathrm{AlON}$ 투명방탄소재 가 기존의 투명방탄소재 대비 매우 우수한 성능을 나타 낸 것으로 알려져 있으며, 기존 방탄소재 대비 $1 / 3$ 두께 수준으로 동일한 방탄성능을 가진다 ${ }^{11}$. 하지만, 기존 적 층유리 방식의 투명방탄소재 대비 비싼 제조단가로 인 하여 생산량을 늘리는 데는 아직까지 한계가 있다. 최근 에는 $\mathrm{AlON}$ 을 방탄소재뿐만 아니라 창, 돔, 렌즈 형태로 제작하여 레이저, 미사일 등 다양한 응용처에 적용하고 자 노력하고 있다(Fig. 2) ${ }^{12)}$.

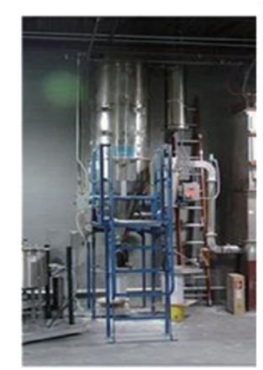
ALON ${ }^{\circledR}$ and Spinel Transparent Ceramics Are Made By Conventional Powder Processing Techniques
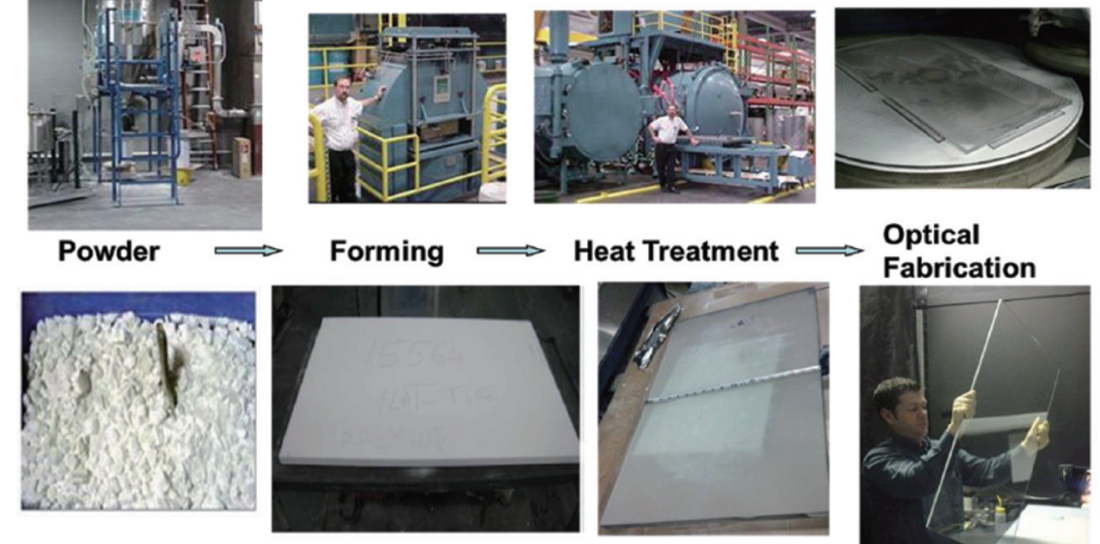

Optical
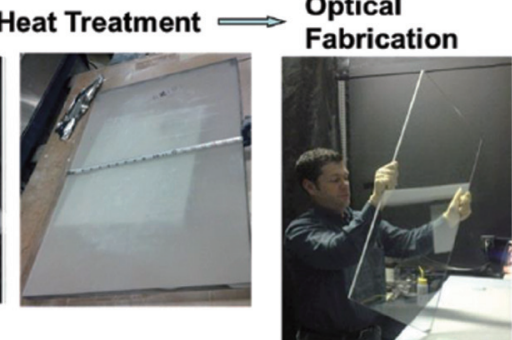

Fig. 1. Surmet사의 ALON 및 Spinel 투명세라믹 제조과정ㅎำ 


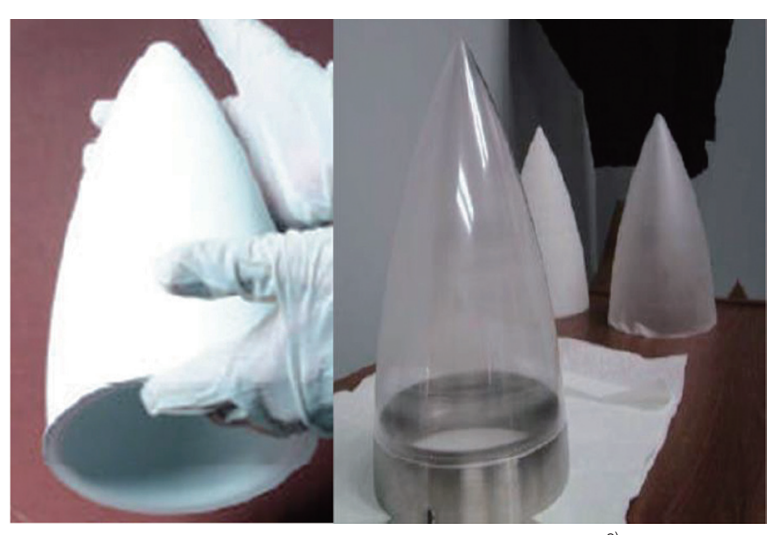

Fig. 2. Surmet사의 ALON 성형체 및 완성된 돔 사진 ${ }^{9)}$

\section{2 적외선용 투명세라믹}

적외선용 투명세라믹은 적외선 파장영역에서 투광도 가 높은 세라믹을 일컫는다. 대표적으로 $\mathrm{Ge}$, 사파이어, $\mathrm{Y}_{2} \mathrm{O}_{3}-\mathrm{MgO}$ nanocomposites, $\mathrm{ZnS}$ 등이 있다. 국내 국 방과학연구소에서는 최근까지 $\mathrm{Ge}$, 사파이어, $\mathrm{Y}_{2} \mathrm{O}_{3}-$ $\mathrm{MgO}, \mathrm{Mg}$ spinel 소재들을 개발해왔으며, 현재까지도 열적, 기계적 물성 향상을 위해 연구개발 중에 있다.

\subsubsection{Mg Spinel}

스피넬의 경우 해외에서는 독일 Fraunhofer IKTS, 미국 US Army Research Lab., 일본 NIMS, 국내에 서는 국방과학연구소, $\mathrm{KIMS}$ 와 같은 연구기관들이 연 구개발 중이다. 투명 스피넬은 방탄뿐 아니라 창, 돔 형
태로도 제작되어 투광성을 요구하는 IR seeker의 보호 용 소재로도 응용되고있다 ${ }^{13)}$. 방탄용 윈도우는 미국 방 산업체인 Armorline 등에서 연구되고 있으며, 동시에 $1 \mathrm{~m}$ 이상의 길이 및 너비를 가진 평판형 스피넬이 생 산되고있다. 적외선 투과창을 위한 스피넬은 TA\&T사 에서 U.S. Army 개발프로그램을 통해 Joint Air-toGround Missile(JAGM, 2008 ) 등의 돔을 제작하는데 성공하였다. 그 밖에 미국 NRL(Naval Research Lab.) 에서도 투명 스피넬의 광학적, 기계적 물성 향상을 위한 연구를 수행해오고 있다.

스피넬, 사파이어, $\mathrm{AlON}$ 세라믹의 투과율을 Fig. 3에 나타내었다 ${ }^{14)}$. 일반적인 스피넬의 IR cut-off는 $6 \mu \mathrm{m}$ 이며, $5.5 \mu \mathrm{m}$ 인 $\mathrm{AlON}$ 보다 길고 $6 \mu \mathrm{m}$ 인 사파이어와 동등한 수준으로 알려져 있다. 광학적으로 두께 $2 \mathrm{~mm}$ 기준 $5 \mu \mathrm{m}$ 파장에서도 $80 \%$ 에 가까운 높은 투과율을 보유하고 있다. 이에 반해, 기계적 강도는 통상적으로 $150 \sim 300 \mathrm{MPa}$ 으로 보고되고 있으며, $\mathrm{AlON}$ 이나 사파 이어 대비 낮은 수준이다. 하지만 스피넬의 탄도특성은 $\mathrm{AlON}$ 및 사파이어와 유사한 수준으로 보고되기도 하였 으며, $4.5 \mu \mathrm{m}$ 이상에서의 고온투과특성은 더 우수한 장 점이 있다 ${ }^{15)}$.

Cubic 결정구조를 갖는 $\mathrm{MgAl}_{2} \mathrm{O}_{4}$ 는 $\mathrm{MgO}$ 와 $\mathrm{Al}_{2} \mathrm{O}_{3}$ 의 화합물로써, $\mathrm{AlON}$ 과 마찬가지로 다결정 형태로 가시 광선 영역에서 투광성을 확보할 수 있다. 스피넬은 주

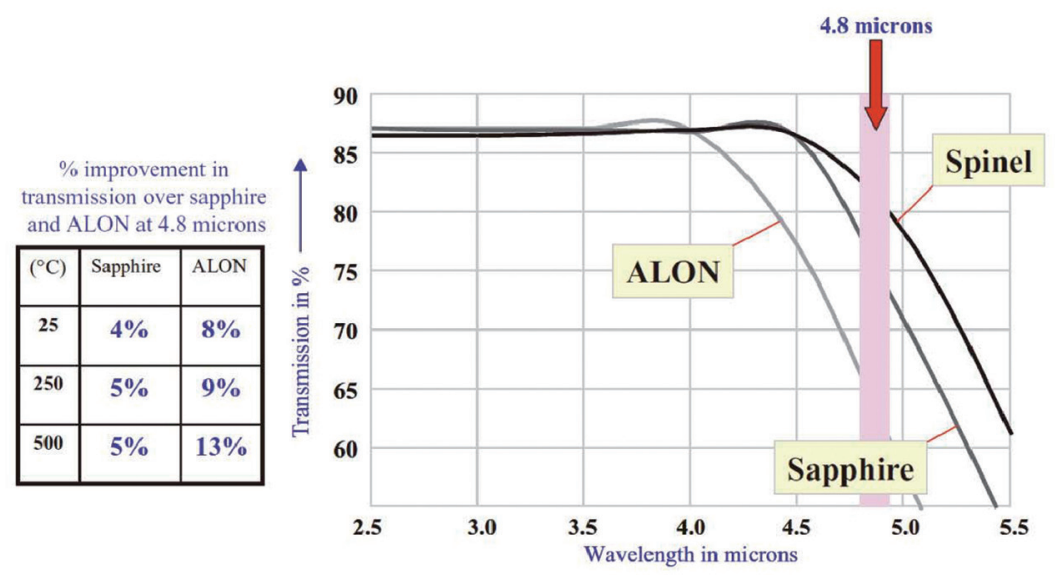

Fig. 3. 스피넬, ALON, 사파이어의 적외선 투과율 비교 그래프 ${ }^{14)}$ 
CERAMIST

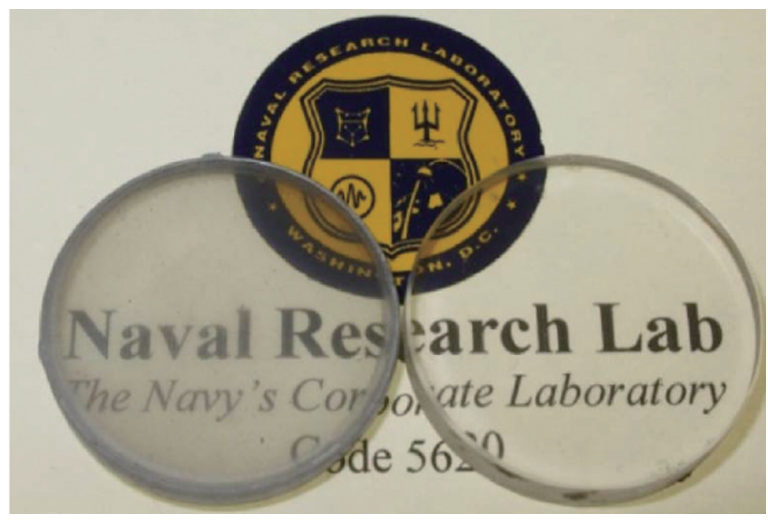

Fig. 4. 상용 분말(좌) 및 산 처리된 고순도 분말(우)을 이용하여 제 조된 투명 스피넬 사진(NRL) ${ }^{22)}$

로 소결/HIP공정, Hot-press/HIP공정, SPS(Spark Plasma Sintering)/HIP공정으로 제작된다. 최종 HIP 공정을 통해 소재의 잔여 기공을 줄임으로써 투광도 와 기계적 물성을 더욱 향상시킬 수 있다. 앞서 소개 한 Surmet사에서 제조하는 $\mathrm{AlON}$ 과 스피넬 공정은 매 우 유사하지만(Sintering/HIP 공정), 분말 준비단계 와 세부적인 공정변수들은 다르다. 스피넬의 조성은 $\mathrm{MgO}+\mathrm{nAl}_{2} \mathrm{O}_{3}$ 이며, 여기서 $\mathrm{n}$ 값은 0.6에서 7.7까지 넓은 범위로 변화시킬 수 있으며, 이에 따른 투광도와 기계 적 물성이 달라질 수 있다. $\mathrm{Krell}$ 등은 $\mathrm{Al}_{2} \mathrm{O}_{3}$ 함량이 증 가할수록 IR cut-off가 감소한다고 보고하였으며, $\mathrm{n}$ 값 이 2.5 일 때 $6 \mu \mathrm{m}$ 이하로 떨어진다 ${ }^{16)}$. 경도 값 또한 $\mathrm{n}$ 값 에 의해서 변하므로 이를 고려한 스피넬 조성설계가 필 요하다. 최근에는 우수한 강도와 경도가 요구되는 IR 센 서의 보호창 역할을 수행하기 위해 입성장을 최대한 억 제시켜 기계적 물성을 크게 향상시키고자 하는 연구가 진행되었다. 미세구조 상에 $28 \mathrm{~nm}$ 정도의 결정립 크기 를 가진 스피넬을 저온고압소결공정을 통해 제조하기도 하였으며, 이를 통해 통상적인 스피넬의 경도 값(13-16 $\mathrm{GPa}$ 보다 큰 $20 \mathrm{GPa}$ 의 경도 값이 보고되었다 ${ }^{17)}$. 스피 넬의 투과율에 영향을 미치는 인자는 초기 분말의 순도 및 입도분포 특성과 2차상 형성, 카본 오염 등이 있을 수 있다. Bernard-Granger, Goldstein, Morita 등은 SPS 소결 시 생성될 수 있는 카본 오염과 그에 따른 투 과율 감소 및 소재의 변색(Discoloration)에 대해서 연
구하였으며, 이를 방지하기 위한 공정변수 제어의 영향 성을 보고하였다 ${ }^{18-20)}$. 초기 분말의 입도분포에 따른 소 결체의 투과율 변화 또한 연구되었으며, 특히 성형체의 기공분포 균일도에 따라 $\mathrm{MgO}-\mathrm{Al}_{2} \mathrm{O}_{3}$ 반응소결의 소결 성이 달라진다고 알려졌다 ${ }^{21}$. NRL에서는 상용분말 대 비 초고순도 산처리된 분말을 이용하여 동일한 투명세 라믹 제조공정 시 투과율이 매우 우수하며 흡수계수가 낮은 스피넬 투과창을 제조하였다(Fig. 4$)^{22)}$.

\subsubsection{Nanocomposite ceramics}

미래의 적외선 추적 미사일용 돔 소재는 운용 전파 환경에서 높은 투과율을 유지하면서도 동시에 더 우수 한 기계적, 열적 물성을 요구하고 있다. 미 Raytheon, Naval Air Center, US Air Force Research Lab. 등은 $\mathrm{Y}_{2} \mathrm{O}_{3}$ 소재의 기계적 강도의 한계를 극복하기 위한 한 가 지 대안으로써 $\mathrm{Y}_{2} \mathrm{O}_{3}-\mathrm{MgO}$ 나노복합소재를 개발하였다 23). 복합소재는 단일상(single phase) 투명세라믹 대비 이종 세라믹 사이에서 입계산란이 일어나기 때문에 이를 최소화하기 위한 수백 나노미터 이하의 결정립 크기를 가진 미세구조가 요구된다. $\mathrm{Y}_{2} \mathrm{O}_{3}$ 와 $\mathrm{MgO}$ 는 소재 간 굴 절률 차이가 크지 않기 때문에 $\left(\mathrm{Y}_{2} \mathrm{O}_{3}: 1.84, \mathrm{MgO}: 1.64\right.$ $@ 4.85 \mu \mathrm{m}$ ) 결정립 크기를 줄임으로써 적외선 영역 투 과율을 충분히 확보할 수 있다(Fig. 5). $\mathrm{MgO}$ 와 $\mathrm{Y}_{2} \mathrm{O}_{3}$ 의 분율을 50:50 vol\%으로 하여 Hot-press 또는 SPS 공 정을 통해 결정립 크기를 $150 \mathrm{~nm}$ 이하로 줄일 수 있었 으며, 이를 통해 중적외선에서 투명하면서도 기계적 강 도와 열충격저항성이 높은 $\mathrm{Y}_{2} \mathrm{O}_{3}-\mathrm{MgO}$ 나노복합소재를 제조할 수 있었다(Fig. 6). 투과율은 $4.85 \mu \mathrm{m}$ 기준 83 $\%$ 까지 보고되었다. 본 나노복합소재의 $\mathrm{MgO}$ 상은 친수 성이 매우 강하기 때문에 $3.25 \mu \mathrm{m}$ 파장의 $\mathrm{H}_{2} \mathrm{O}$ 흡수 현 상이 두드러지며 이는 여전히 해결과제로 남아있다.

산화물 중에서도 $\mathrm{MgO}$ 소재 자체의 열전도도가 높 은 편이기 때문에 $\mathrm{Y}_{2} \mathrm{O}_{3}$ 와 복합화한 경우, $\mathrm{Y}_{2} \mathrm{O}_{3}(14 \mathrm{~W} /$ $\mathrm{mK}$ ) 대비 열전도도 값이 2 배 가량 높은 것으로 알려져 있다 ${ }^{23)}$. 기계적 강도 또한 결정립 크기가 작기 때문에 우수하다. 공정변수 최적화로 인해 결정립 크기가 작아 질수록 Hall-Petch 현상에 의한 기계적 강도 향상이 있 

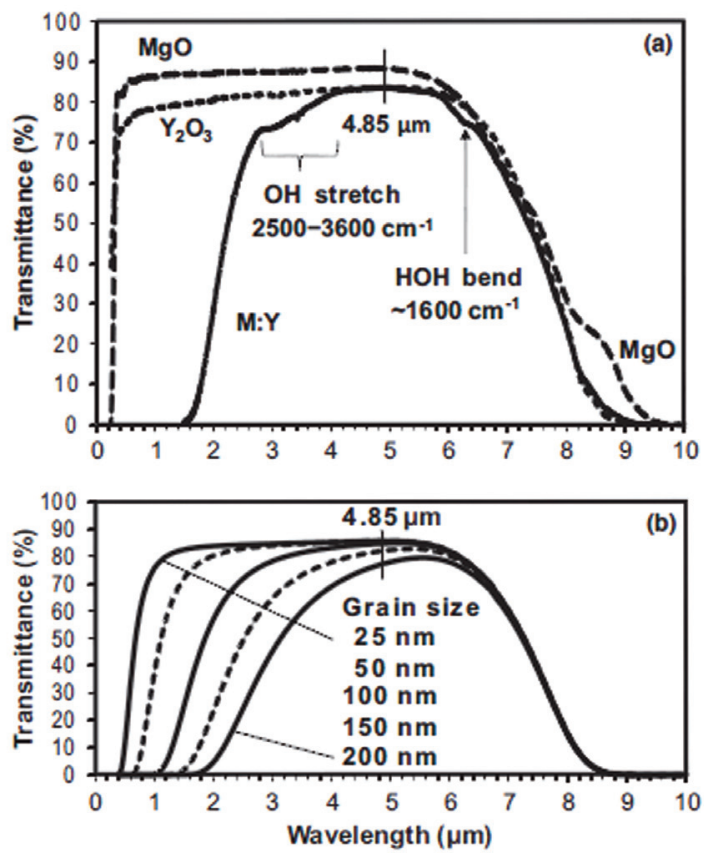

Fig. 5. 단결정 $\mathrm{MgO}$, 다결정 $\mathrm{Y}_{2} \mathrm{O}_{3}$ 및 $\mathrm{Y}_{2} \mathrm{O}_{3}: \mathrm{MgO}$ 나노복합소재의 결정립 크기에 따른 투과율 비교 그래프 ${ }^{23}$

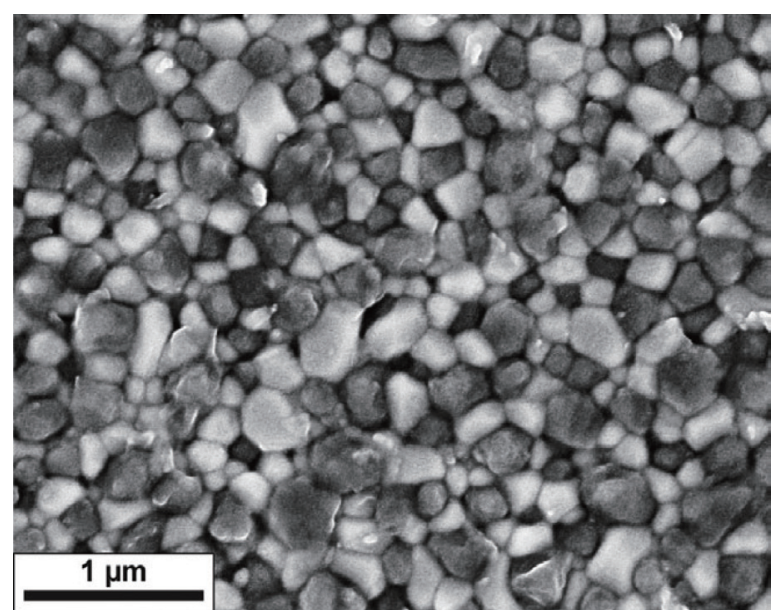

Fig. 6. 50:50 vol\% $\mathrm{Y}_{2} \mathrm{O}_{3}: \mathrm{MgO}$ 나노복합소재의 미세구조 ${ }^{23)}$

으며, 굴곡강도는 상온에서 $660 \mathrm{MPa}$, 고온 $\left(600{ }^{\circ} \mathrm{C}\right)$ 에 서 $485 \mathrm{MPa}$ 까지 보고되었다. $\mathrm{Y}_{2} \mathrm{O}_{3}-\mathrm{MgO}$ 나노복합소 재의 열충격저항지수는 $3.8\left(\times 10^{3} \mathrm{~W} / \mathrm{m}\right)$ 로써, c-Plane sapphire의 8.6 대비 낮지만 스피넬(0.9-1.7)이나 $\mathrm{Y}_{2} \mathrm{O}_{3}(1.0-1.4)$ 대비 높은 수준이다 ${ }^{23)}$.

최근 $\mathrm{Y}_{2} \mathrm{O}_{3}-\mathrm{MgO}$ 나노복합소재는 분말 준비단계가 최종
물성을 결정하는 데 큰 영향을 주는 것으로 알려졌다 ${ }^{24)}$. 입 자크기 및 분포도 영향을 주지만, $\mathrm{Y}_{2} \mathrm{O}_{3}$ 와 $\mathrm{MgO}$ 입자가 균일하게 섞여있는 분말이 소결 시 입성장을 제어하는 데 효과적이다.

화염분무법(Flame pyroloysis technique)을 비롯하 여 sol-gel합성법, 연소법 등 많은 분말합성기술이 보고 되었으며, 그에 따른 소결특성 및 투과율, 강도 변화가 연구되어왔다.

\subsubsection{ZnS}

$\mathrm{ZnS}$ 소재는 이론적으로 가시광에서부터 장적외선 (LWIR)영역까지 투광성이 확보되기 때문에 다중대역 $\mathrm{ZnS}($ Multispectral ZnS)로써 seeker의 보호 창 역할 이 기대되는 소재이다. 해외 II-VI사, VITRON, ISP Optics, SCHOTT, KODAK 등을 비롯하여 국내에서도 많은 업체들이 개발 및 제조하고 있으며, 통상적으로는 CVD(Chemical Vapor Deposition)법을 이용한다. CVD 로 제조된 $\mathrm{ZnS}$ 는 추가적인 $\mathrm{HIP}$ 공정을 거쳐서 Cleartran 이라는 상호로 불리는 다중대역 $\mathrm{ZnS}$ 가 된다 ${ }^{25)}$. $\mathrm{CVD} / \mathrm{HIP}$ 공정을 통해 제조된 다중대역 $\mathrm{ZnS}$ 소재는 대 부분 열전도도 $27 \mathrm{~W} / \mathrm{mK}$, 4점곡강도 $60 \mathrm{MPa}$, 경도 $150 \mathrm{~kg} / \mathrm{mm}^{2}$ 수준의 물성을 보여준다. 음속 이상의 영 역에서 사용되기 위해서는 기계적 물성을 향상이 필수 적으로 요구된다.

$\mathrm{ZnS}$ 소재의 기계적 물성을 향상시키기 위한 방법으로 결정립 크기를 줄이고자 하는 연구가 수행되어왔다. 기 존 $\mathrm{CVD} / \mathrm{HIP}$ 공정 특성 상 수십 $\mu \mathrm{m}$ 이상의 결정립 크 기를 갖게 되는 반면, Hot-press 또는 SPS 소결을 통 한 제조방법은 상대적으로 작은 결정립 크기(수 $\mu \mathrm{m}$ 수 준)로 제어할 수 있다. 이에 많은 연구자들이 $\mathrm{ZnS}$ 분말 프로세싱과 소결 공정을 통해 $\mathrm{ZnS}$ 투명화 연구를 수행 해왔다(Fig. 7 ${ }^{26)}$. 그러나, $\mathrm{ZnS}$ 는 상온에서 cubic상 이 외에 hexagonal상이 추가로 존재할 수 있으며, $800{ }^{\circ} \mathrm{C}$ 이상의 고온에서 hexagonal상의 양이 더욱 늘어나는 문제점이 있다. 따라서 고온 소결 시 필연적으로 발생 할 수 밖에 없는 hexagonal상 때문에 $\mathrm{ZnS}$ 소결체의 가 시광영역 투광성을 잃어버리게 된다. 최근에는 고온 공 


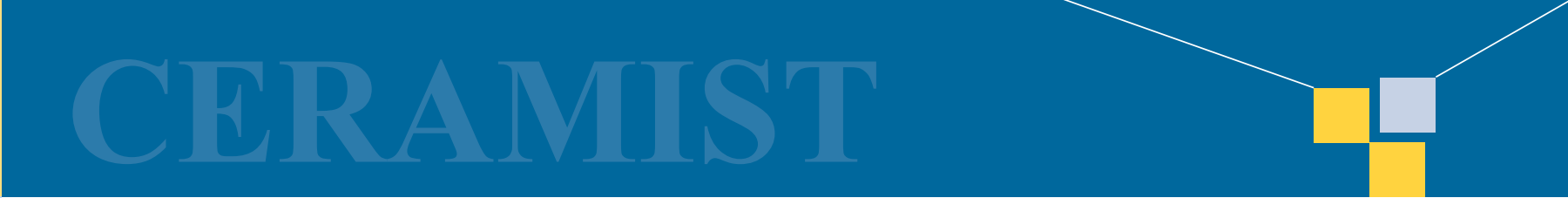

특 집 ㅁㅁ 정욱기, 이기수, 최재호

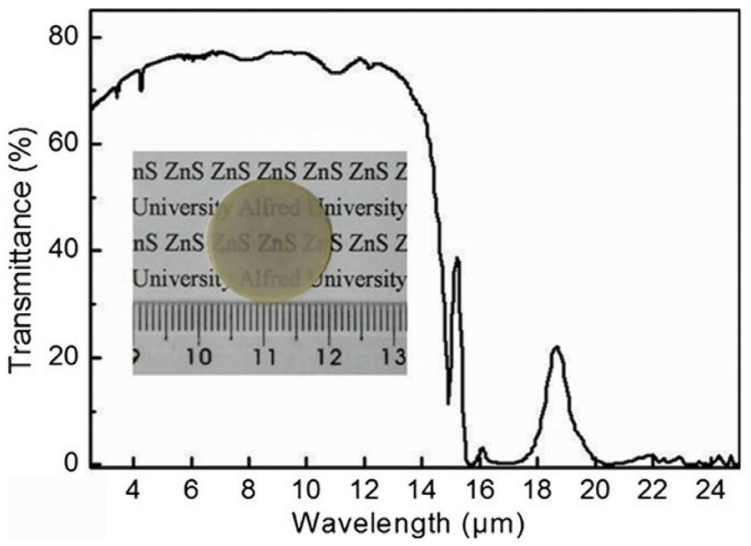

Fig. 7. Hot-press로 제작된 $0.6 \mathrm{~mm}$ 두께 ZnS 투명세라믹 사진 및 투과율 그래프리

정 시 hexagonal상을 줄이기 위한 연구결과들이 보고 되기도 하였다 ${ }^{27)} \mathrm{ZnS}$ 소재의 낮은 기계적 물성을 향상 시키는 데는 여전히 한계가 따르기 때문에 표면 하드 코 팅을 위한 연구결과들도 보고되었다 ${ }^{28)}$. 표면 코팅으로는 경도와 탄성계수(Young's Moudulus)가 높으며 동시에 투과율이 높고 IR cutoff가 긴 소재들로 연구가 되어왔 다. 그 중에서도 특히 다이아몬드는 탄성계수 값(1,050 $\mathrm{GPa})$ 및 경도 $(70 \mathrm{GPa})$ 가 매우 높다. 본 $\mathrm{ZnS}$ 하드 코팅 기술의 주된 이슈는 열팽창계수 차이로 인한 박리(Delamination)현상이다. 그 밖에도 $\mathrm{ZnS} /$ 다이아몬드 복합 화, 다이아몬드 창 등을 개발하여 $\mathrm{ZnS}$ 소재를 대체하기 위해 연구되었으나, 비싼 공정 비용 등 한계가 있다.

\section{3 레이저 세라믹}

고체 레이저(Solid-state laser) 분야에서, 기존의 단 결정의 한계점을 극복할 수 있는 다결정 투명세라믹 레 이저가 개발되어왔다. 다결정 투명세라믹은 큰 부피로 제작할 수 있어서 고출력을 얻을 수 있으며, 고농도 도 핑이 가능하다. 1990년대 일본에서는 300-600 mW 수 준에서 다결정 Nd:YAG(Yttrium Aluminum Garnet, $\left.\mathrm{Y}_{3} \mathrm{Al}_{5} \mathrm{O}_{12}\right)$ 세라믹을 사용하여 단결정 $\mathrm{Nd}: \mathrm{YAG}$ 와 견줄 만한 $60 \%$ 대의 발진 효율을 가지는 고체 레이저를 선보 였다 ${ }^{29)}$. 이후 수많은 Nd:YAG 다결정 투명세라믹 소재 의 제조방법 및 특성 평가에 관한 연구들이 이루어졌다 (Fig. 8, 9) ${ }^{30,31)}$.

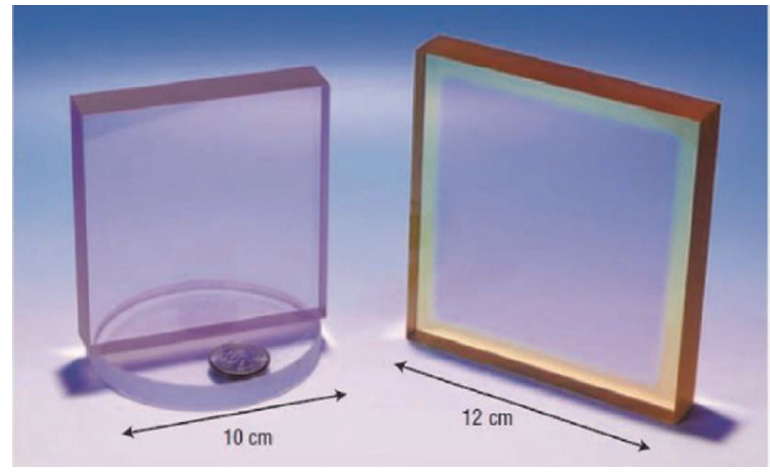

Fig. 8. Nd:YAG 세라믹 $100 \times 100 \times 20$ mm3 (좌) 및 (우) Sm 클래딩 ${ }^{30)}$

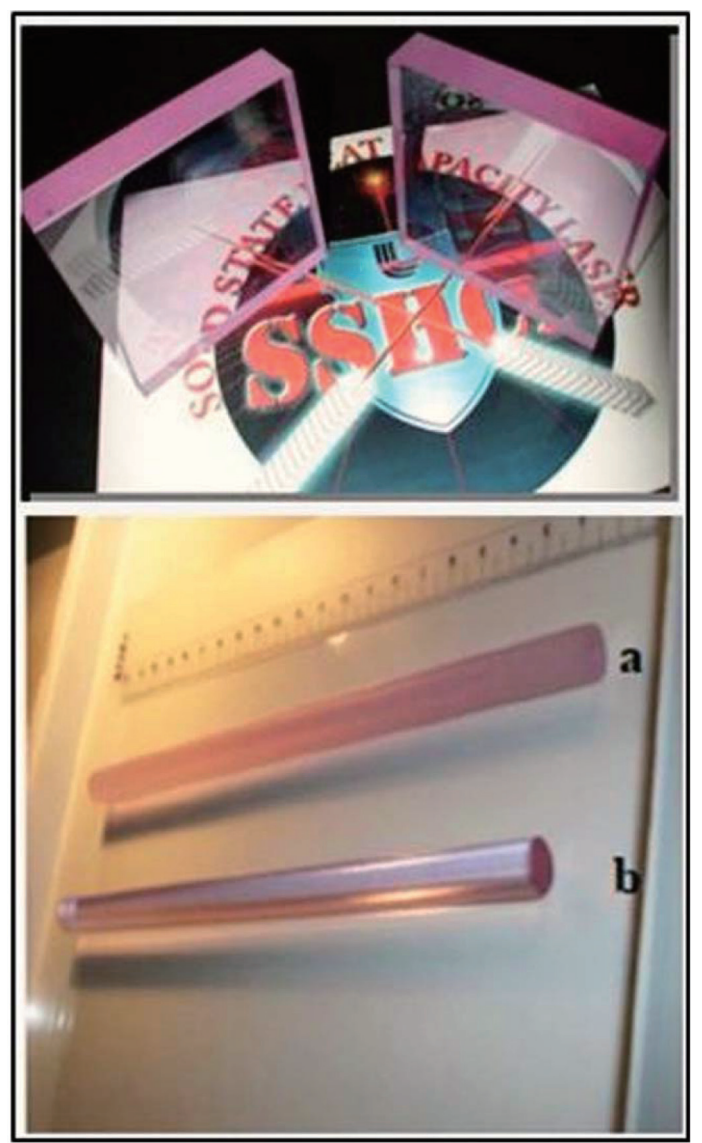

Fig. 9. 다양한 크기 및 모양을 가진 $\mathrm{Nd}^{3+}$ :YAG 투명세라믹 소재 사진 $^{311}$

기존의 레이저 호스트물질인 $\mathrm{YAG}$ 는 높은 열팽창계 수와 $10 \mathrm{~W} / \mathrm{mK}$ 이하의 낮은 열전도도를 가지며, 이러 한 낮은 열전도도를 가지는 호스트는 고출력 시 온도 경 사에 의한 빔의 왜곡과 복굴절이 발생하기 때문에 출력 
을 높이는 데 한계가 있었다. Ikesue 등은 이를 해결하 기 위하여 $\mathrm{Nd}$ 농도 분포가 다른 YAG 성형체들을 적층 소결하여 $\mathrm{YAG}$ 의 낮은 열전도도 문제를 극복하고자 하 였달). 그 밖에도 새로운 레이저 호스트 물질들도 활발 이 연구되고 있다. 특히, 기존 YAG에 비해서 상대적으 로 열전도도가 높은 삼이산화물 $\left(\mathrm{Lu}_{2} \mathrm{O}_{3}, \mathrm{Y}_{2} \mathrm{O}_{3}, \mathrm{Sc}_{2} \mathrm{O}_{3}\right)$ 들 은 도핑 농도가 증가하여도 열전도도 감소가 적으며, 높 은 흡수 및 방출 단면적을 가져서 고출력 레이저 응용에 더욱 적합하다고 알려졌다 ${ }^{33)}$. 다결정 투명세라믹들은 기 공 산란뿐 아니라, 입계(grain boundaries)에서의 레이 저 산란도 심각하다고 보고되고 있다. 이를 해결하기 위 해서는 미 산란(Mie scattering) 이론, 레일리(Rayleigh scattering) 산란 이론을 모두 고려한 매우 고도화된 세 라믹 공정기술이 필요하다. 다결정 입계의 이차 상 및 불순물은 고출력 레이저가 가지는 치명적 한계 중 하나 이며, 공정 시 초기 분말의 순도를 높이는 것이 매우 중 요하다.

\section{3. 결론}

투명세라믹의 제조방법에 따른 물성 연구는 세라믹 공정 기술과 함께 많은 발전이 있었다. 최근에는 국내 에서도 민군 과제 등을 통해 산학연에서 많은 연구개발 이 이루어지고 있다. 특히, 방탄/적외선 윈도우용 다결 정 투명세라믹스 분야에서 $\mathrm{AlON}$, 단결정 $\mathrm{Al}_{2} \mathrm{O}_{3}, \mathrm{Y}_{2} \mathrm{O}_{3}-$ $\mathrm{MgO}$ 나노복합소재, $\mathrm{MgAl}_{2} \mathrm{O}_{4}, \mathrm{ZnS}, \mathrm{Ge}$ 등과 같은 투 명세라믹 제조기술에 대한 연구성과들이 있었다. 군수 분야에 사용되기 위한 투명세라믹 소재는 극한환경에서 운용되기 위해 기계적 강도와 열 물성을 더욱 향상시키 기 위한 여러가지 과제들이 남아있다. 특히, 다결정 세 라믹의 투명화 확보를 위해 기공을 최소 $100 \mathrm{ppm}$ 미만 으로 제어하면서도 동시에 필요한 무기체계 운용에 적 합한 물성치에 도달하기 위해서는 아직까지 넘어야 할 산들이 많다. 또한, 고체 레이저용 투명세라믹스는 기존 의 방탄/윈도우용 소재 제조기술보다 더욱 높은 수준의 공정 난이도를 가지고 있다. 앞으로 가까운 미래에 고품 질의 레이저 투명세라믹 개발을 위해서는 그동안 축적
된 투명세라믹 공정기술 노하우들이 크게 기여할 수 있 을 것으로 기대된다.

\section{REFERENCES}

1. A. Krell, J. Klimke, T. Hutzler, Opt. Mater., 311144 (2009).

2. Parimal J. Patel, Gary A. Gilde, Peter G. Dehmer, James W. McCauley, "Transparent ceramics for armor and EM window applications", Proc. SPIE., 4102, Inorganic Optical Materials II (25 October 2000).

3. D. C. Harris, Infrared Phys. Technol., 39185 (1988).

4. W. Kim, G. Villalobos, C. Baker, J. Frantz, B. Shaw, S. Bayya, B. Sadowski, M. Hunt, I. Aggarwal, J. Sanghera, Opt. Eng., 5221003 (2012).

5. G. Subhash, "Transparent armor materials”, Exp. Mech., 53 1-2 (2013).

6. Parimal J. Patel, Jeffrey J. Swab, Gary A. Gilde, "Fracture properties and behavior of transparent ceramics", Proc. SPIE., 4102, Inorganic Optical Materials II (25 October 2000).

7. A. F. Dericioglu, Y. Kagawa, "Effect of grain boundary microcracking on the light transmittance of sintered transparent $\mathrm{MgAl}_{2} \mathrm{O}_{4}$ ", J. Eur. Ceram. Soc., 23 [6] 951959 (2003).

8. T. G. Talladay, D. W. Templeton, "Glass armor- an overview”, Int. J. Appl. Glass. Sci., 5 [4] 331 (2014).

9. L. M. Goldman, M. Smith, M. Ramisetty, S. Jha, S. Sastri, "Conformal ALON and spinel windows", Proc. SPIE., 10985, Window and Dome Technologies and Materials XVI, 109850G (13 May 2019).

10. Shan Y, Zhang Z., Sun X., Xu J., Qin Q., Li J., "Further, experimental investigation on fast densification mechanism of bimodal powder during pressureless sintering of transparent AlON ceramics", Ceram. Int., 43/11 8195-8201 (2017).

11. M. Grujicic, W. C. Bell, B. Pandurangan, "Design and material selection guidelines and strategies for transparent armor systems", J. Mater. Design., 34 808-819 (2012). 
12. Joseph M. Wahl, Thomas M. Hartnett, Lee M. Goldman, Richard Twedt, Charles Warner, "Recent advances in ALON optical ceramic", Proc. SPIE., 5786 Window and Dome Technologies and Materials IX (18 May 2005).

13. A. A. DiGiovanni, A. LaRoche, L. Schubel, L. Fehrenbacher, D. W. Roy, "Polycrystalline transparent spinel domes for multimode seeker applications", Proc. SPIE., 6545, Window and Dome Technologies and Materials X 6545, 654514 (2 May 2007).

14. A. A. DiGiovanni, L. Fehrenbacher, and D. W. Roy,"Hard Transparent Domes and windows from magnesium aluminate spinel”, Proc. SPIE., 5786 56-63 (2005).

15. C Zhang, J W Cao, J B Guo, F F Liu, C Wang, G W Hasi and Z Z Guo, "The research on transparent armor material technology", J. Phys. Conf. Ser., 1507 102014 (2020).

16. A. Krell, K. Waetzig and J. Klimke, "Influence of the structure of $\mathrm{MgO} \cdot \mathrm{nAl}_{2} \mathrm{O}_{3}$ spinel lattices on transparent ceramics processing and properties", $J$. Eur. Ceram. Soc., 32 [11] 2887-2898 (2012).

17. J. A. Wollmershauser, B. N. Feigelson, E. P.Gorzkowski, C. T. Ellis, R. Goswami, S. B. Qadri, J. G.Tischler, F. J. Kub and R. K. Everett, "An extened hardness limit in bulk nanoceramics", Acta Mater., 69 9-16 (2014).

18. A. Goldstein, "Correlation between $\mathrm{MgAl}_{2} \mathrm{O}_{4}$-spinel structure, processing factors and functional properties of transparent parts (progress review)", J. Eur. Ceram. Soc., 32 [11] 2869-2886 (2012).

19. G. Bernard-Granger, N. Benameur, C. Guizard and M. Nygren, "Influence of graphite contamination on the optical properties of transparent spinel obtained by spark plasma sintering", Scr. Mater., 60 [3] 164-167 (2009).

20. K. Morita, B-N. Kim, H. Yoshida, K. Hiraga and Y. Sakka, "Influence of spark plasma sintering(SPS) conditions on transmission of $\mathrm{MgAl}_{2} \mathrm{O}_{4}$ spinel", $J$. Am. Ceram. Soc., 98 [2] 378-385 (2015).

21. G. Bonnefont, G. Fantozzi, S. Trombert and L.
Bonneau, "Fine-grained transparent $\mathrm{MgAl}_{2} \mathrm{O}_{4}$ spinel obtained by spark plasma sintering of commercially available nanopowders", Ceram. Int., 38 [1] 131-140 (2012).

22. W. Kim, G. Villalobos, C. Baker, J. Frantz, B. Shaw, S. Bayya, B. Sadowski, M. Hunt, B. Rock, I. Aggarwaland J. Sanghera, "Overview of transparent optical ceramics for high-energy lasers at NRL", Appl. Opt., 54 [31] F210-F221 (2015).

23. D. C. Harris, L. R. Cambrea, L. F. Johnson, R. T. Seaver, M. Baronowski, R. Gentilman, C. Scott Nordahl, T. Gattuso, S. Silberstein, P. Rogan, T. Hartnett, B. Zelinski, W. Sunne, E. Fest, W. Howard Poisl, C. B. Willingham, G. Turri, C. Warren, M. Bass, D. E. Zelmon, S. M. Goodrich, "Properties of an infrared-transparent $\mathrm{MgO}: \mathrm{Y}_{2} \mathrm{O}_{3}$ nanocomposite", J. Am. Ceram. Soc., 96 3828-3835 (2013).

24. H. J. Ma, W. K. Jung, C. Baek, D. K. Kim, "Influence of microstructure control on optical and mechanical properties of infrared transparent $\mathrm{Y}_{2} \mathrm{O}_{3}-\mathrm{MgO}$ nanocomposite", J. Eur. Ceram. Soc., 37 [15] 49024911(2017).

25. P. Ramavath, P. Biswas, R. Johnson, G. J. Reddy, P. Laxminarayana, "Hot isostatic pressing of $\mathrm{ZnS}$ powder and CVD ZnS ceramics: comparative evaluation of physicochemical, microstructural and transmission properties", Trans. Ind. Ceram. Soc., 73 299-302 (2014).

26. Y. Li, Y. Wu, "Transparent and luminescent $\mathrm{ZnS}$ consolidated by vacuum hot pressing method", 98 [10] 2972-2975 (2015).

27. J. S. McCloy, R. Korenstein, B. Zelinski, "Effects of temperature, pressure, and metal promoter on the recrystallized structure and optical transmission of chemical vapor deposited zinc sulfide", J. Am. Ceram. Soc., 92 [8] 1725-1731 (2009).

28. D. C. Harris, "Frontiers in infrared window and dome materials", Proc. SPIE., 2552, Infrared Technology XXI (8 September 1995).

29. A. Ikesue, T. Kinoshita, K. Kamata, and K. Yoshida, "Fabrication and optical properties of high- 
performance polycrystalline Nd:YAG ceramics for solid state lasers,"J. Am. Ceram. Soc., 78 103-1040 (1955).

30. R. M. Yamamoto et al., in Proc. Adv. Solid State Photon., Nara, Japan, WC5, (2008).

31. R. Feldman and Y. Shimony, "Strength and strengthening of polycrystalline (ceramic) laser components"; presented at the 6th International

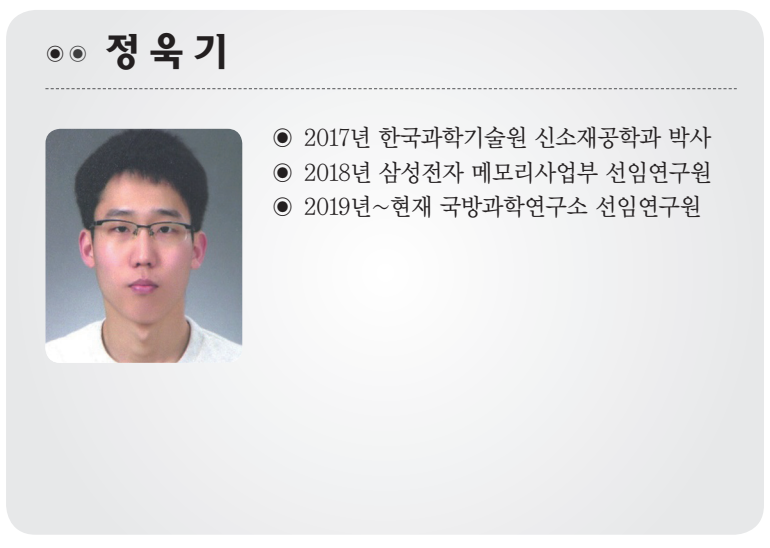

\section{○。 최 재호}

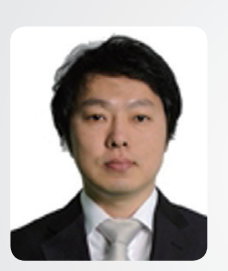

() 2015년 한국과학기술원 생명화학공학과 박사

○ 2001년 현재 국방과학연구소 연구원. 선임연구원, 책임연구원
Symposium on Transparent Ceramics for Photonic Applications, Munster, Germany, December 6-8 (2010).

32. T. Kamimura, T. Okamoto, Y. L. Aung, and A. Ikesue, in CLEO 2007, Baltimore, Maryland, CThT6 (2007).

33. J. Sanghera, W. Kim, G. Villalobos, B. Shaw, C.Baker, J. Frantz, B. Sadowski, and I. Aggarwal, “Ceramic Laser Materials", Mater., 5 258-277 (2012).

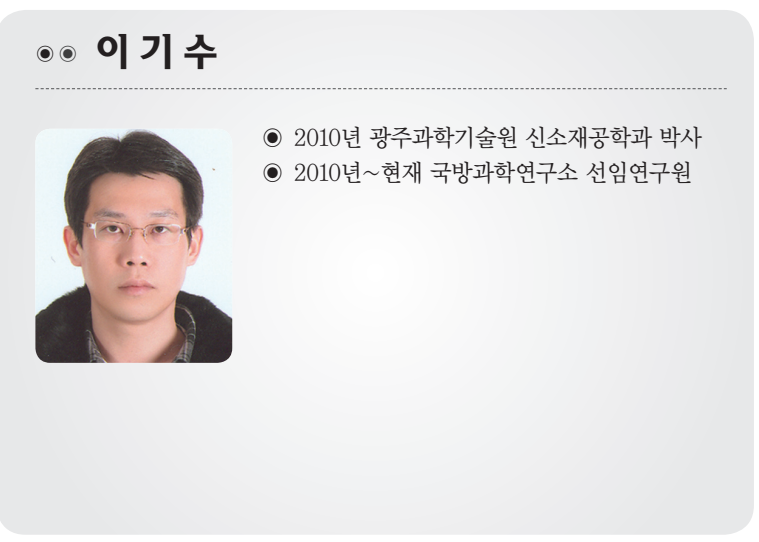

